\title{
Exploring school levels of digital readiness in pandemic time
}

\author{
Alice Roffi ${ }^{a}$, Maria Ranieri ${ }^{b}$, Isabella Brunic \\ a University of Florence, Italy, alice.roffi@unifi.it, https://orcid.org/0000-0002-2683-3743 \\ bUniversity of Florence, Italy, maria.ranier@unifi.it, https://orcid.org/0000-0002-8080-5436 \\ c University of Florence, Italy, isabella.bruni@unifi.it, https://orcid.org/0000-0003-2426-5129
}

\begin{abstract}
COVID-19 lockdown measures adopted by governments in March 2020 have impacted our society as never happened before. The school system was not an exception. Interventions to allow students for distance learning through the support of 'old' (e.g. TV) or 'new' media (e.g. digital platforms) have been promoted, involving millions of students and teachers worldwide. This paper presents a study on school leaders and teachers' perceptions on the school levels of digital readiness through the comparison of their views before and during the lockdown. The participation in the EU project DETECT provided the context for exploring the school levels of digital readiness. Data were collected belonging to two different phases and allowing to investigate teachers' perceptions in using technologies for remote teaching. The school is living an unprecedent period where dramatic experiences are also disclosing new opportunities. Our study found that school had a strategy before the COVID-19 emergency, but it was too focused on infrastructures' acquisition, while the development of competences on the side of both teachers and students requires an investment in long-term training, up to the point of reshaping the current teaching practices and also planning for interdisciplinary educational activities addressed to the students.
\end{abstract}

Keywords: digital literacy; educational innovation; secondary school; continuing professional development; teacher

\section{Introduction}

COVID-19 lockdown measures adopted by governments in early March 2020 have impacted our society as never happened before. The school system was not an exception. In Europe, up to $90 \%$ of countries decided to close their schools (European Centre for Disease Prevention and Control, 2020). Interventions to allow students for distance learning through the support of 'old' (e.g. TV) or 'new' media (e.g. digital platforms) have been promoted, involving millions of students and teachers all around the world (UNESCO, 2020).

The pandemic emergency has completely upset the way of doing school worldwide, highlighting both the relevance of digital tools and the challenges that the digital reshaping of teaching and learning practices entails. Indeed, digital technologies allowed to preserve the educational continuity between the teachers and the students, but at the same time, these latter had to measure with new tools for teaching and learning.

To what extent the school and its actors were prepared to the 'digital turn' imposed by the COVID-19 emergency? How school leaders and teachers felt when faced with the need to rethink their current practices in a digital sense?

This paper presents a study on school leaders and teachers' perceptions on the school levels of digital readiness through the comparison of their views before and during the lockdown phase. In the first section, the background of the study is provided including the methodology, while in the second section, the main results are described and discussed.

\section{Background}

Several reports have been published in the last months on the impact of COVID-19 emergency on schooling. Overall, available data report that teachers often felt unprepared (Carretero Gomez et al., 2020; Ranieri et al., 2020), while trying 
to reuse materials to cope with the situation (EEF, 2020). According to the School Education Gateway Survey (2020), $66.9 \%$ of teachers, in Europe, have being teaching online for the first time and many teachers faced problems to access technologies. In many cases, this led to simply replicate face-to-face classroom practices, ignoring the constraints of the new setting (Giovannella et al., 2020; Ranieri et al., 2020). One of the barriers preventing the appropriate integration of technology in teaching practices was the teachers' level of digital competence and the lack of proper training. Even before the COVID-19 crisis, teachers expressed a strong need for training on digital education, with $18 \%$ on average in OECD countries indicating it as a maximum need for training (OECD, 2019). Moreover, according to OECD's Teaching and Learning International Survey (TALIS), just 53\% of teachers have their students frequently or always using ICT for projects or classwork (OECD, 2020).

Other studies underline the need for improving teachers' digital skills for designing effective and inclusive digital (or blended) learning activities (Mor et al., 2013). The role of teacher as a 'designer of learning' has been already pointed out before the COVID-19 emergency, underlining that the goal for teachers is to develop suitable digital pedagogies to better meet student needs (Bocconi et al., 2018).

Several frameworks and self-assessment tools have been developed to help educators reflecting on their digital practices (Bocconi et al., 2018). In particular, at European level, the most relevant tool is the SELFIE (Self-reflection on Effective Learning by Fostering the use of Innovative Educational technologies) questionnaire, an online self-reflection tool to support schools in their use of digital technologies for educational purposes. This tool was adopted in this study to compare teachers' perceptions of their digital preparation before the pandemic with teachers' views gathered through a focus group carried out during the lockdown phase. Details on methods are presented in the next section.

\section{Research context and methods}

The Technology Education Laboratory (TEL) (University of Florence) participation in the EU project 'DEveloping TEachers' Critical digital liTeracies' (DETECT) provided the context for exploring the school levels of digital readiness. Since the project started in the pre-COVID-19 period and went on during the lockdown, data were collected belonging to two different phases and allowing to investigate teachers' perceptions in using technologies for remote teaching. DETECT is a three-year project led by the University of Hull (UK) and involving partners from United Kingdom, Finland, Italy and Spain.

The project aims at supporting educators in developing critical digital literacies on the use of ICT in school. In Italy, TEL cooperated with the Sassetti Peruzzi Institute, a vocational and technical school based in Florence, with more than 1,000 students (50\% of which from 51 different nationalities) and 150 teachers.

\subsection{Research questions}

The specific research questions of this study are as follows:

Research question 1 (RQ1): What is the digital readiness level of the Sassetti Peruzzi Institute (Florence, Italy) school in terms of infrastructure and leadership in the pre-COVID period (RQ1a) and in the lockdown phase (RQ1b)?

Research question 2 (RQ2): What is the digital readiness level of teachers, in terms of digital competence and professional development in the pre-COVID period (RQ2a) and in the lockdown phase (RQ2b)?

Research question 3 (RQ3): What is the digital readiness level of students, in terms of digital competence and autonomy in learning with technologies in the pre-COVID period (RQ3a) and in the lockdown phase (RQ3b)?

\subsection{Methods and tools}

The study was conducted on February-May 2020, using the following research tools: the SELFIE questionnaire, addressing 3 members of the school leaders' team, 34 teachers and 163 students (I, II and III classes; male and female, age range 14-16); a headmaster interview; and 3 focus groups with 17 teachers. The SELFIE questionnaire and the headmaster interview were performed before the lockdown period, while the focus groups were realised during the lockdown (Table 1). 
Table 1. Tools and targets of research.

\begin{tabular}{|c|c|c|}
\hline Tool & Target & Period \\
\hline \multirow{3}{*}{ SELFIE } & $\begin{array}{c}3 \text { members of the school leaders' team, } \\
\text { including the headmaster }\end{array}$ & 10-17 February 2020 \\
\hline & 34 teachers & (pre-COVID-19) \\
\hline & 163 students & \\
\hline \multirow[t]{4}{*}{ Headmaster Interview } & 1 headmaster & $\begin{array}{l}18 \text { February } 2020 \\
\text { (pre-COVID-19) }\end{array}$ \\
\hline & In total, 17 teachers $(T)$ & \\
\hline & (8 humanities teachers, 6 STEM teachers & Focus Group 1: 5th May 2020 \\
\hline & and 3 special needs teachers) & Focus Group 2: 11th May 2020 \\
\hline \multirow[t]{3}{*}{ Focus Group (FG) } & Focus Group 1: 7 teachers & Focus Group 3: 21st May 2020 \\
\hline & Focus Group 2: 6 teachers & (during COVID-19) \\
\hline & Focus Group 3: 4 teachers & \\
\hline
\end{tabular}

The SELFIE questionnaire aims at collecting anonymously school leaders', teachers' and students' views. Answers are given on a scale 1 (strongly disagree) to 5 (strongly agree) and displayed as aggregate data, through the production of an interactive report for each item. Items are organised in different thematic areas: A, Leadership; B, Infrastructure and equipment; C, Continuing professional development; D, Teaching and learning; E, Assessment practices; F, Student digital competence. Further items on the use of technologies for teaching and learning are adoption of technologies, confidence in using technologies, factors inhibiting the use of technologies and time use technologies.

SELFIE was administered in Italian with the support of the headmaster of Sassetti Peruzzi Institute. The results have been analysed per item, highlighting strengths and weaknesses.

The headmaster interview was a semi-structured interview intended to collect qualitative data on the digital preparation and strategy of the school.

The focus groups were organised around 5 themes: A, General use of digital technologies; B, Conceptions of critical digital literacies; C, Opinions about what aspects of Critical Digital Literacy (CDL) schools should provide for students; D, Examples of the participants' current pedagogical practices to support students' CDL; E, Evaluation of current situation in the partner school. They were carried out online for COVID-19 limitations. Interviews were examined through a thematic analysis based on DETECT CDL's framework including the following dimensions: 1) technology use, 2) data literacies, 3) information and digital content use, 4) digital content creation, 5) digital communication and collaboration, 6) digital well-being and safety, 7) digital citizenship and 8) digital teaching and learning.

\section{Results}

\subsection{Pre-COVID-19 school profile}

Overall, SELFIE answers indicate a positive self-perception in terms of digital readiness: all agree with the statements on adequate digital preparation, although to different extents when considering the school leaders, teachers and students. In the following section, the higher and lower scores of statements are reported for each area to highlight the main strengths and weaknesses. The mean value of the answers' score for respondents has been calculated, according to the scale 1 = strongly disagree to 5 = strongly agree.

RQ1a: What is the digital readiness level of the school in terms of infrastructure and leadership in the pre-COVID-19 period? 
To answer this question, results from SELFIE - Area A on leadership and Area B on infrastructure and equipment have been considered together with the headmaster interview. As for SELFIE, the main results are as follows:

Area A: the highest score (4.7/5) was reported in the answers of school leaders for the items on school digital strategy and its implementation with the involvement of teachers. The members of the school leaders' team strongly agreed that the school has a digital strategy that has been developed in collaboration with the teachers. Interestingly, teachers attributed to these items a lower score $(3.4 / 5)$ with respect to that given by school leaders.

The lowest score of this area (2.8/5) has been reported in the answer of teachers for the item related to the time to use technology. Teachers' answers concentrate between 'disagree and slightly agree' to have time to explore how to improve their teaching with digital technologies. On the contrary, from the school leaders' perspective, this item reached a higher score (3.7/5; Table 2).

Area B: the highest score $(5 / 5)$ was reported in the answer of school leaders for the items related to the presence of infrastructures, digital devices for teaching, Internet access and technical support. Instead, teachers attributed a lower score to these items $(3.9,3.7,4.1,3.5 / 5)$.

The lowest score of Area B (2.5/5) was reported in the answer of teachers for the item related to the presence of libraries/repositories and to the availability of a database of trainers. On the contrary, school leaders gave a higher score $(3.3,4.3 / 5$; Table 3$)$.

Table 2. Area A: Leadership.

\begin{tabular}{|c|c|c|c|}
\hline Item code & Item title & School leaders & Teachers \\
\hline A1 & Presence of school digital strategy & 4.7 & 3.4 \\
\hline $\mathrm{A} 2$ & $\begin{array}{l}\text { Development of school digital strategy in } \\
\text { collaboration with teachers }\end{array}$ & 4.7 & 3.4 \\
\hline A3 & $\begin{array}{l}\text { New ways of teaching with digital } \\
\text { technologies }\end{array}$ & 4.7 & 3.4 \\
\hline A4 & Progress review & 4.3 & 3.2 \\
\hline A5 & Discussion on the use of technology & 4.3 & 3.1 \\
\hline A6 & Partnership & 4.0 & 3.0 \\
\hline A7 & Time to explore digital technology & 3.7 & 2.8 \\
\hline A8 & Copyright and licensing rules & 4.7 & 3.3 \\
\hline A9 & $\begin{array}{c}\text { Involvement of company in the digital } \\
\text { strategy }\end{array}$ & 3.7 & 2.7 \\
\hline
\end{tabular}

Table 3. Area B: Infrastructure and equipment.

\begin{tabular}{cccc}
\hline Item code & Item title & School leaders & Teachers \\
\hline B1 & Infrastructure & 5.0 & 3.9 \\
B2 & Digital device for teaching & 5.0 & 3.7 \\
B3 & Internet access & 5.0 & 4.1 \\
B4 & Technical support & 3.6 \\
B5 & Data protection & 5.0 & 3.6 \\
B6 & Digital device for learning & 4.7 & 2.9 \\
B7 & Bring your own device & 4.0 & 2.7 \\
B9 & Assistive technologies & 2.7 & 3.2 \\
B10 & Online libraries/repositories & 4.0 & 2.5
\end{tabular}


Coming to the headmaster interview, it confirms the results from the SELFIE. Indeed, the headmaster underlined the effort done to provide proper infrastructures and equipment to favour the integration of digital technologies for teaching: for example, as the interviewed stated, '... in the last 4 years, we tried to make all classes digital, with Internet connection, one computer per class, maxi screens connected to the computer'. Furthermore, the headmaster emphasised as a main component of the school's digital strategy, the approach that was adopted to promote a conscious use of mobile phones or social media by the students: '...on one hand, we try to make students more aware that the use of phones at school is not the same they have at home, so at school the phone can be used only in the case of teaching activities that foreseen their use ... on the other hand, there are several ongoing projects on social media use for teaching to increase the digital awareness in a work-based context ...'

$R Q 2 a:$ What is the digital readiness level of teachers, in terms of digital competence and professional development in the pre-COVID-19 period?

To answer this question, results from SELFIE - Area C on continuing professional development, Area D on teaching and learning and Area E on assessment practices, and the additional items adoption of technologies, confidence in using technologies, factors inhibiting the use of technologies and time use technologies - have been considered together with the headmaster interview. As for SELFIE, the main results are as follows:

Area C: the highest score (5/5) was reported in the answers of school leaders for the items related to sharing teachers' experience on digital teaching. School leaders strongly agree to support teachers in sharing experience with the school community. Interestingly, teachers attributed to these items a lower score (3.4/5). The lowest score in Area C (3/5) was reported in the answer of teachers for the item related to the possibility to have CPD opportunities in the use of digital technologies, specific to the courses they teach. On the contrary, from the school leaders' perspective this, item reached a higher score $(4.3 / 5$; Table 4$)$.

Area D: the highest score (4.7/5) was reported in the answers of school leaders, who strongly agreed that teachers engaged students in using digital technologies for cross-curricular projects. Interestingly, teachers attributed to these items a lower score (3.7/5). Other items are at the same lowest level (3.3/5) in the answer of teachers, who slightly agree to use virtual learning environments with students, while school leaders' answers reached a higher score (4/5; Table 5).

Area E: the highest score (5/5) was reported in the item related to the feedback to the students: school leaders strongly agreed that teachers use digital technologies to provide timely feedback to students, while teachers only slightly agree $(3.2 / 5)$. The lowest score (2.8/5) was reached by teachers' answers, close to slightly agree on the use digital technologies to enable students to provide feedback on other students' work (Table 6).

Table 4. Area C: Continuing professional development.

\begin{tabular}{cccc}
\hline Item code & Item title & School leaders & Teachers \\
\hline C1 & CPD needs & 4.3 & 3.2 \\
C2 & Participation in CPD & 4.7 & 3.3 \\
C3 & Sharing experiences & 5.0 & 3.4 \\
C4 & CPD opportunities & 4.3 & 3.0 \\
\hline
\end{tabular}

Table 5. Area D: Teaching and learning.

\begin{tabular}{cccc}
\hline Item code & Item title & School leaders & Teachers \\
\hline D1 & Online educational resources & 4.0 & 4.2 \\
D2 & Creating digital resources & 3.3 & 3.6 \\
D3 & Using virtual learning environments & 4.0 & 3.3
\end{tabular}


Exploring school levels of digital readiness in pandemic time

Roffi,, A, Ranieri, M. \& Bruni, I.

D4

D5

D6

D7

D8

D9

D10

D11
Communicating with the school

community

$$
\text { Keeping data secure }
$$

Tailoring student's need

Fostering creativity

Engaging students

Student collaboration

Cross-curricular projects

Open educational resources
$4.0 \quad 4.1$

$\begin{array}{ll}4.3 & 3.9\end{array}$

$4.3 \quad 4.0$

$4.3 \quad 3.9$

$\begin{array}{ll}4.3 & 3.7\end{array}$

$4.7 \quad 3.7$

$\begin{array}{ll}3.7 & 3.9\end{array}$

Table 6. Area E: Assessment practices.

\begin{tabular}{cccc}
\hline Item code & Item title & School leaders & Teachers \\
\hline E1 & Digital assessment & 4.3 & 3.6 \\
E2 & Assessing skills & 4.7 & 3.6 \\
E3 & Timely feedback & 5.0 & 3.2 \\
E4 & Self-reflection on learning & 4.0 & 3.2 \\
E5 & Feedback to other students & 3.7 & 2.8 \\
E6 & Documenting learning & 4.3 & 3.5 \\
E7 & Using data to improve learning & 4.3 & 3.6 \\
E8 & Valuing skills developed outside school & 4.0 & 3.4 \\
\hline
\end{tabular}

Adoption of technologies: all school leaders agreed on the sentence 'I am usually among innovators who try out new technologies', while $58 \%$ of teachers opted for 'I tend to be an early adopter where I see clear benefits', $21 \%$ 'I tend to use digital technologies at the pace of the majority of my colleagues', $15 \%$ 'I am usually among innovators who try out new technologies', and 6\% 'I tend to use digital technologies after the majority of my colleagues'.

Confidence in using technologies: according to the scale used for the answer ( 1 not at all confident, 2 not confident, 3 a little bit confident, 4 confident, 5 very confident), it emerged this pattern of confidence in using technology for teaching (Table 7). This item foresees only the answers of teachers.

Table 7. Confidence in using technology for teaching.

\begin{tabular}{lc}
\hline & Score \\
\hline Class teaching & 3.8 \\
Preparing lessons & 3.7 \\
Communication & 3.7 \\
Feedback and support & 3.4 \\
\hline
\end{tabular}




\section{Exploring school levels of digital readiness in pandemic time Roffi, , A, Ranieri, M. \& Bruni, I.}

Factors inhibiting use of technologies: according to the answer of school leaders, it can be noted that all factors have the same level of importance in inhibiting the use of technologies for teaching. Instead, in teacher's results, it was created a factors' rating, where 'lack of time for teachers', 'low digital competence of teachers' and 'insufficient digital equipment' are in first 3 positions (Table 8).

Table 8. Factors inhibiting use of technologies.

\begin{tabular}{lll}
\hline & School leaders (\%) & Teachers (\%) \\
\hline Lack of funding & 33.3 & 35.3 \\
Insufficient digital equipment & - & 38.2 \\
Unreliable or slow Internet connection & - & 35.3 \\
School space restrictions & 33.3 & 35.3 \\
Limited or no technical support & - & 20.6 \\
Lack of time for teachers & 33.3 & 64.7 \\
Low digital competence of teachers & 33.3 & 47.1 \\
Low digital competence of students & 33.3 & - \\
Other motivation & 33.3 & - \\
\hline
\end{tabular}

Percentage of time dedicated to the digital teaching: according to the answers of teachers, 2 of 34 teachers spent 0 $10 \%$ of time in digital technology teaching, 11 of 34 spent $11-25 \%$ of time, 8 of 34 spent $26-50 \%$ of time, 9 of 34 spent $51-75 \%$ of time and 3 of 34 spent $76-100 \%$ of time.

As for the headmaster interview, it emerged that the level of adoption of technologies for teaching was influenced by the different levels of digital competence: when low, it was a barrier; when high, it supported the management of the challenges related to the high level of multiculturality, while increasing the flexibility of the educational offer.

Another important aspect was about teacher training. According to the headmaster, it should not be focused on the use of specific tools, but on the diverse opportunities offered by technologies, particularly referring to reaching: ' ... a confidence level in technology use to be able to speak with students; this could change the relation between teacherstudents and the type of support we can give them in terms of consciousness use'.

RQ3a: What is the digital readiness level of students, in terms of digital competence and autonomy in learning with technologies in the pre-COVID-19 period?

To answer this question, results from SELFIE - Area F on student digital competence - have been considered together with the headmaster interview. As for SELFIE, the main results are as follows:

Area F: the highest score $(5 / 5)$ was reported in the answers of school leaders, who strongly agreed that in their school, students learn how to behave safely and responsibly online and develop digital skills related to their vocational qualification. Interestingly, teachers' opinions are in between 'slightly agree and agree' in the same items (3.6, 3.7, 3.9/5).

The lowest score of Area F (3.2/5) was reported in the answers of teachers, for the item related to coding in school $(3.7 / 5)$

Table 9. Area F: Student digital competence.

\begin{tabular}{cccc}
\hline Item code & Item title & School leaders & Teachers \\
\hline F1 & Digital skills across subjects & 4.7 & 3.4 \\
F2 & Safe behaviour & 5.0 & 3.6 \\
F3 & Responsible behaviour & 5.0 & 3.7 \\
F4 & Checking the quality of information & 4.7 & 3.6
\end{tabular}




\section{Exploring school levels of digital readiness in pandemic time Roffi, , A, Ranieri, M. \& Bruni, I.}

$\begin{array}{lccc}\text { F5 } & \text { Giving credit to others' work } & 4.3 & 3.5 \\ \text { F6 } & \text { Creating digital content } & 4.7 & 3.7 \\ \text { F7 } & \text { Learning to communicate } & 4.7 & 3.8 \\ \text { F8 } & \text { Learning coding and programming } & 3.7 & 3.2 \\ \text { F9 } & \text { Solving technical problems } & 3.7 & 3.3 \\ \text { F10 } & \text { Skills for vocational qualification } & 5.0 & 3.9\end{array}$

From the headmaster interview, it emerged that students have digital competences to some extent and this allows them to carry on several learning activities using technologies, enhancing their digital competence and becoming the 'technological support' of the teachers. As stated by the headmaster, 'One positive thing is that teachers often ask students for help when they have to carry on a teaching activity requiring the use of ICTs such as the creation of a digital music or a video'.

\subsection{Post-COVID-19 school awareness}

\section{$R Q 1 b:$ What is the digital readiness level of the school in terms of infrastructure and leadership in the lockdown} phase?

From teachers' focus groups, the image of a school with underdeveloped uses of ICTs for teaching emerged, especially for technical problems: as a teacher observed, 'This year I couldn't do anything, also because I had some special classes, with many Chinese students, not having a computer at home. There are difficulties also to use school ICT labs’ (T1, FG3).

However, some positive aspects were mentioned such as the school effort to allow students to access remote teaching or the adoption of equipment like shared drives and the digital register which was useful during the lockdown: 'Our school is striving to provide students with all the necessary things to access remote teaching. [...] In this moment, it is very helpful to use already adopted tools such as Drive and electronic register' (T4, FG1).

$R Q 2 b$ : What is the digital readiness level of teachers, in terms of digital competence and professional development in the lockdown phase?

As for teachers' digital readiness, teachers firstly pointed out their commitment for self-training to conduct emergency remote education. This generated both a sort of digital stress for lack of competences and some satisfaction for advancements in professional knowledge: as a teacher commented, 'I was self-trained and satisfied with myself, because with the help of tutorials and the collaboration with my colleagues I've been able to overcome several difficulties' (T4, FG1).

Second, teachers underlined their difficulties in using technologies for the lack of digital competences and acknowledged the need for constant use of ICT for greater integration: 'I'm fascinated by the use of technologies, but I recognise that it requires a continuous use' (T5, FG1), Furthermore, sometimes the improvement of these skills has been left to teacher's autonomous initiative, with no specific courses: 'The critical issue is that the training was done autonomously by teachers' (T2, FG2).

Third, teachers expressed different attitudes towards the integration of technologies into teaching practices. The general feeling was that teachers felt digitally unprepared and this feeling prevented them from properly supporting students' digital creativity: 'Teachers are less prepared to support students' creativity and growth in terms of digital technologies' (T2, FG2). Furthermore, teachers found difficult to reshape the traditional curriculum with the support of digital tools, especially in certain areas: 'We are not able yet to integrate the use of new technologies within the teaching of literacy, writing, reading and so on, we are not ready to promote students' basic skills while using also digital technologies' (T4, FG2).

Fourth, teachers reported their difficulties to manage remote teaching due to the lack of experience in distance learning ('The remote teaching highlighted how we believed to be able to manage the distance, but instead it showed us how we really don't know how to do it' (T6, FG2)) and to technical or cultural problems ('I've tried to use classroom for managing groups, but I was not able to reach all students, thus I've stopped using it' (T1, FG3)).

Lastly, the teachers emphasised their difficulty in student's assessment due to the lack of proper tools to evaluate them: 'I'm searching for a system for the online assessment. A system able to guarantee an objective assessment, preventing students for cheating' (T4, FG3).

$R Q 3 b$ : What is the digital readiness level of students, in terms of digital competence and autonomy in learning with technologies in the lockdown phase?

First, students were represented as being familiar with social network sites or video games, but less able to send an email or download the digital version of a book, showing to be digitally unprepared: 'Students' ICT competences are 
limited. I see them unprepared, despite they spent many hours in ICT labs. Some students didn't know how to upload a file or how to create a word document' (T2, FG2).

Second, it was also clear that the students would need appropriate equipment to develop their digital competences, since in some cases the school is the only place to enhance them. As a teacher explained, 'Students have only the school time to practice with digital technologies and some of them didn't have any digital tools at home' (T4, FG2). This means that the problem of digital divide still the Italian families with some social groups having better technical and cultural access to ICT than others.

Third, the teachers agreed that improving student's digital competence is really challenging since it would require a cross-curricular approach. As a teacher declared, 'Competences regarding all school subjects cannot be taught with a transmissive lesson. Students should be involved and have the possibility to use the tools they need to put in practice what they have learnt' (T3, FG1).

\section{Discussion and conclusion}

According to the SELFIE results, the profile of Sassetti Peruzzi School as for educational technologies' adoption in the teaching and learning process looks generally good. The most relevant aspect concerns the presence of a strategy of development of digital education, although the perceptions of the school leaders' team were more positive than the teachers, as reported also in Bocconi et al. (2020). This strategy was focused on improving the technological equipment and providing Internet connection in all classrooms. Not surprisingly, teachers recognise the benefits of such investments, reporting scores over the mean as for aspects such as Internet access, availability of teaching devices and technical support. However, the issue raised regarding the digital strategy suggests that greater involvement of teachers in the discussion on digital innovation should be encouraged. Moreover, from the pre-COVID-19 survey, a main problem clearly emerged, that is the lack of students' learning devices. Compared to the number of students attending the school, the technological equipment was insufficient to cover their needs, and also bring your own device approach was underdeveloped, likely for the absence of a specific school policy and the fear of misbehaviour, despite projects on digital awareness were in progress in the school.

The COVID-19 emergency had a pushing effect in this regard: as teachers reported, during the lockdown they tried to provide all students with technical tools to allow them to take part in remote teaching activities. Clearly, since this dramatic event was unplanned, it was challenging, even because it was harder for students to familiarise online with the new devices. A conservative approach was, therefore, preferred during the lockdown, favouring the use of simple tools already in use, such as cloud services and electronic registers. Another relevant problem concerned the teaching related to the use of school laboratories that were inaccessible from a distance. These challenges indicate the importance of including in a digital strategy also the design of blended and online activities to benefit from the affordances of digital tools and not be unprepared in emergency situations (Giovannella et al., 2020).

As for teachers' practices, according to SELFIE results, the use of technologies is reported with scores higher than 3.5 out of 5 into many areas of activities such as organisational communication, use and production of educational resources, students' involvement, and creativity, while lower results are reported for use of learning environments and for evaluation and feedback, especially when student-centred approaches are taken into account such as peer-feedback. Consistently with other studies (OECD, 2019), we can then conclude that digital practices are widespread, but not systematic yet: digital teaching is not a current practice for the $40 \%$ of the respondents, who estimate to spend a maximum of $25 \%$ of their teaching time using technologies. Not surprisingly and similarly to other studies (e.g. Albò et al., 2020), teachers identify as barriers for ICT use the lack of time for and the low level of digital competence: a clear need of continuing professional development emerges from their responses, reflecting data reported on wider studies (OECD, 2020), especially on how to integrate them into the teaching practices regardless of the subject topic.

The pandemic lockdown phase was a catalyst to find time for the improvement of their digital skills: facing the emergency and the need to be able to implement remote teaching, teachers were finally forced to self-train themselves to the use of new tools such as video conferencing systems and software for video lesson production. The effort was huge, but peer-mentoring among colleagues made it happen (see also JRC, in press). In parallel, the satisfaction for succeeding in managing the emergency situation easily led to the awareness of the importance of integrating ICTs within daily teaching practices: only this level of adoption can produce a real change and consolidate teachers' digital competences.

As for students, the responses before the COVID-19 emergency depict a good level of digital competences, with teachers reporting scores above 3.5 for almost all items of the battery, except for specific programming skills. However, the experience of distance learning revealed a rather different reality. Although students are considered as digital natives and are familiar with technologies such as social networks and smartphones, similarly to other studies (JRC, in press), we found that the remote teaching experience has brought out two types of digital divides. The first level of divide relies on student's socio-economic background, which influences Internet and computer access from home. The second level of digital divide is, instead, linked to the level of digital competence, given that being always online does not entail to be

Research on Education and Media. Vol. 12, N. 2, Year 2020 - ISSN: 2037-0830 
able to carry out activities such as creating a word document or using learning platforms. In this regard, the main challenge is engaging students with activities for digital skills' development, since they are not strictly connected with a specific discipline: an interdisciplinary approach would be a better strategy to get concrete results.

Although timely, this study has some limitations. First, considering the low number of participants involved and the nature of the sample, which was not statistically representative, its results cannot be generalised. Second, while the knowledge of the teachers' subject of teaching would have been useful to better understand specific benefits and obstacles of pedagogic innovation, the limited number of participants prevented the possibility to deeply address the influence of the subject matter. However, future studies in this respect will be undertaken to increase the relevance of self-reflection for professional development and innovation in specific subject areas.

\section{Acknowledgments}

This work has been conducted under the support of Erasmus Plus program, Key Action 2 of the European Union, within the project "DEveloping TEachers' Critical digital liTeracies - DETECT”, coordinated by Hull University (UK). The DETECT's Consortium is the only responsible of these contents, not reflecting the point of view of European Union.

\section{References}

Albó, L., Beardsley, M., Martínez-Moreno, J., Santos, P., \& Hernández-Leo, D. (2020, September). Emergency Remote Teaching: Capturing Teacher Experiences in Spain with SELFIE. In European Conference on Technology Enhanced Learning (pp. 318-331). Springer, Cham.

Bocconi, S., Panesi, S. (2018) Teachers' professional learning and competence in the digital era. The DigCompEdu framework (page 39-49). In Teacher Education \& Training on ICT between Europe and Latin America, ISBN 97888-255-2102-3, DOI 10.4399/97888255210234.

Bocconi, S., Panesi, S., \& Kampylis, P. (2020). Fostering the digital competence of schools: piloting SELFIE in the Italian education context. IEEE Revista Iberoamericana de Tecnologias del Aprendizaje, 15(4), 417-425.

Carretero Gomez, S., Napierala, J., Bessios, A., Mägi, E., Pugacewicz, A., Ranieri, M., Triquet, K., Lombaerts, K., Robledo Bottcher, N., Montanari, M. and Gonzalez Vazquez, I. (2021) What did we learn from schooling practices during the COVID-19 lockdown, EUR 30559 EN, Publications Office of the European Union, Luxembourg, doi:10.2760/135208, JRC123654.

Di Pietro, G., Biagi, F., Costa, P., Karpiński Z., Mazza, J. (2020) The likely impact of COVID-19 on education: Reflections based on the existing literature and international datasets, EUR 30275 EN, Publications Office of the European Union, Luxembourg, ISBN 978-92-76-19937-3, doi:10.2760/126686, JRC121071.

Education Endowment Foundation (2020) Impact of school closures on the attainment gap: Rapid Evidence Assessment, London: Education Endowment Foundation.

European Centre for Disease Prevention and Control (2020). COVID-19 in children and the role of school settings in COVID-19 transmission, European Centre for Disease Prevention and Control, Stockholm.

Giovannella, C., Passarelli, M., Persico, D. (2020). Measuring the effect of the Covid-19 pandemic on the Italian Learning Ecosystems at the steady state: a school teachers' perspective. Interaction Design and Architecture (s) Journal (IxD\&A), (45).

Mor, Y., Craft, B., Hernández-Leo, D. (2013). The art and science of learning design: Editorial. Research in Learning Technology, 21.

OECD, 2019. How's Life in the Digital Age? Opportunities and Risks of the Digital Transformation for People's Wellbeing. [Online] Available at: https://doi.org/10.1787/9789264311800-en.

OECD (2020), TALIS 2018 Results (Volume II): Teachers and School Leaders as Valued Professionals, TALIS, OECD Publishing, Paris, https://doi.org/10.1787/19cf08df-en.

Ranieri M., Gaggioli C., Borges M.K. (2020) La didattica alla prova del Covid-19 In Italia. Uno studio sulla scuola primaria. https://doi.org/10.5212/PraxEduc.v.15.16307.079

$\begin{array}{lllll}\text { School Education } & \text { Gateway } & \text { Survey } & \text { (2020). } & \text { Retrieved }\end{array}$ https://www.schooleducationgateway.eu/en/pub/viewpoints/surveys/survey-on-online-teaching.htm 